\title{
Incidence of Cytomegalovirus Retinitis in the Era of Highly Active Antiretroviral Therapy
}

\author{
Elizabeth A. Sugar, $\mathrm{PhD}^{1,2}$, Douglas A. Jabs, MD, MBA ${ }^{1,3,4}$, Alka Ahuja, MS ${ }^{1}$, Jennifer E. \\ Thorne, MD, PhD ${ }^{1,5}$, Ronald P. Danis, MD $^{6}$, and Curtis L. Meinert, $\mathrm{PhD}^{1,2}$ for the Studies of \\ the Ocular Complications of AIDS Research Group \\ 1Department of Epidemiology, Johns Hopkins University Bloomberg School of Public Health, \\ Baltimore, MD \\ ${ }^{2}$ Department of Biostatistics, Johns Hopkins University Bloomberg School of Public Health, \\ Baltimore, MD \\ ${ }^{3}$ Department of Ophthalmology, Mount Sinai School of Medicine, New York, NY \\ ${ }^{4}$ Department of Medicine, Mount Sinai School of Medicine, New York, NY \\ ${ }^{5}$ The Division of Ocular Immunology, The Wilmer Eye Institute, The Johns Hopkins School of \\ Medicine, Baltimore, MD \\ ${ }^{6}$ Department of Ophthalmology and Visual Sciences, University of Wisconsin, Madison, Madison, \\ WI
}

\begin{abstract}
Purpose-To estimate the incidence of cytomegalovirus (CMV) retinitis in the era of highly active antiretroviral therapy (HAART) and to characterize the factors associated with increased risk of CMV retinitis.
\end{abstract}

Design-Prospective cohort study

\footnotetext{
(C) 2011 Elsevier Inc. All rights reserved.

Corresponding Author: Elizabeth A. Sugar, PhD, Center for Clinical Trials, Departments of Epidemiology and Biostatistics, The Johns Hopkins University Bloomberg School of Public Health, 615 N. Wolfe Street, Baltimore, MD 21204. Tel: 410-614-7837 Fax: 410-955-0958 esugar@jhsph.edu.

Reprints: Douglas A. Jabs, SOCA Chairman's Office, Department of Ophthalmology, Mount Sinai School of Medicine, One Gustave L. Levy Place, Box 1183, New York, NY 10029-6574; douglas.jabs@mssm.edu.

${ }^{*}$ Members of the SOCA Research Group are available as Supplemental Material.

Financial Disclosures: Dr. Jabs serves as a member of the board for Applied Genetic Technologies and as a consultant for the following: Abbott Laboratories, Alcon Laboratories, Allergan Pharmaceutical Corporation, Corcept Therapeutics, GenenTech, Genzyme Corporation, GlaxoSmithKline, Novartis Pharmaceuticals Corporation, Roche Pharmaceuticals. Dr. Thorne serves on a scientific advisory board for Allergan, Inc. and has been a consultant for Heron Evidence Development Ltd. All other authors have no financial disclosures to report.

Contributions of Authors: Design and conduct of study (EAS, DAJ, AA, JET, RPD, CLM); collection and management of the data (EAS, AA, SOCA Research Group); provision of patients and resources (DAJ, RPD, CLM, SOCA Research Group); analysis and interpretation of the data (EAS, DAJ, AA, JET, RPD, CLM); preparation of manuscript (EAS, DAJ, AA, JET); review and approval of the manuscript (EAS, DAJ, AA, JET, RPD, CLM, SOCA Research Group)

Statement about Conformity: This study was approved by the local IRBs of each SOCA clinical center and the 3 resources centers (Chairman's office, Coordinating center, Reading Center). This study is in compliance with HIPAA regulations and is performed in compliance with the Declaration of Helsinki.

Publisher's Disclaimer: This is a PDF file of an unedited manuscript that has been accepted for publication. As a service to our customers we are providing this early version of the manuscript. The manuscript will undergo copyediting, typesetting, and review of the resulting proof before it is published in its final citable form. Please note that during the production process errors may be discovered which could affect the content, and all legal disclaimers that apply to the journal pertain.
} 
Methods-1600 participants with acquired immune deficiency syndrome (AIDS) but without CMV retinitis at enrollment who completed at least one follow-up visit in the Longitudinal Study of the Ocular Complications of AIDS (LSOCA) were seen every 6 months to obtain disease and treatment history, ophthalmic examination, and laboratory testing. Incidence of CMV retinitis and risk factors for incident CMV retinitis were assessed.

Results-The incidence rate of CMV retinitis in individuals with AIDS was 0.36/100 person years (PY) based upon 29 incident cases during 8,134 person-years of follow-up. The rate was higher for those with a CD4+ T cell count at the immediately prior visit below 50 cells $/ \mu \mathrm{L}$ (3.89/100 PY, $\mathrm{p}<0.01)$, whereas only one individual with a CD4+ T cell count of 50-99 cells $/ \mu \mathrm{L}$ and two individuals with a CD4+ T cell count $>100$ cells/ $\mu \mathrm{L}$ developed CMV retinitis. Having a $\mathrm{CD} 4+\mathrm{T}$ cell count below 50 cells/ $\mu \mathrm{L}$ at the clinical visit prior to $\mathrm{CMV}$ retinitis evaluation was the single most important risk factor (HR: 136, 95\% CI: 30 to 605, $\mathrm{p}<0.0001$ ) for developing retinitis.

Conclusions-Patients with AIDS, especially those with severely compromised immune systems, remain at risk for developing CMV retinitis in the HAART era, although the incidence rate is reduced from that observed in the pre-HAART era.

\section{Introduction}

Cytomegalovirus (CMV) retinitis is the most common ocular opportunistic infection in patients with the acquired immunodeficiency syndrome (AIDS). ${ }^{1}$ Prior to the introduction of highly active antiretroviral therapy (HAART), approximately $30 \%$ of individuals infected with the human immunodeficiency virus (HIV) developed CMV retinitis at some point during their lifetime. ${ }^{2}$ The initiation of widespread use of HAART in the mid-1990s dramatically altered the course of AIDS. Treatment with HAART suppresses HIV replication, resulting in a drop in HIV load and in immune recovery, as evidenced by a rise in CD4+ T cell counts. As a result, the incidence rates of opportunistic infections, such as CMV retinitis, have declined but they have not dropped to zero. ${ }^{3-5}$ Patients primarily remain at risk for developing CMV retinitis either because of delayed diagnosis of HIV infection or because they are noncompliant, intolerant of, or unresponsive to HAART. ${ }^{6-9}$ Despite the substantial reduction in the incidence of CMV retinitis and the development of more effective therapies, CMV retinitis remains an important cause of visual loss in patients with AIDS during the HAART era. ${ }^{10-12}$ Therefore, quantifying the incidence rate and understanding the risk factors associated with the development of CMV retinitis remains important both for patients and health care providers.

The Longitudinal Studies of the Ocular Complications of AIDS (LSOCA) ${ }^{13}$ was initiated to study the occurrence and consequences of ocular complications among patients with AIDS during the HAART era. A previous analysis estimating the incidence of CMV retinitis was performed based on the prevalence data obtained at the time of enrollment. ${ }^{13}$ However, since the cohort was enriched deliberately with individuals having an opportunistic infection, such as CMV retinitis, that analysis provides an upper bound for the estimate of the incidence, which is still unknown. ${ }^{6,13}$ Herein we present an analysis to assess the incidence rate and risk factors for CMV retinitis based upon data collected from patients free of CMV retinitis at enrollment in the LSOCA cohort.

\section{Patients and Methods}

LSOCA is a multicenter, prospective, observational study of patients with AIDS recruited from ophthalmology clinics specializing in infectious disease or retinal clinics that was initiated in 1998. Patients aged 13 or greater with a diagnosis of AIDS were eligible, regardless of immunologic or CMV retinitis status. ${ }^{13,14}$ AIDS was diagnosed according to 
the 1993 Centers for Disease Control and Prevention Revised Surveillance Case Definition. ${ }^{15}$ The study protocol and questionnaires were reviewed and approved by the institutional review boards at each of the participating clinical centers, and at the resource centers and the study was conducted in accordance with the principles of the Declaration of Helsinki. All participants gave written informed consent. For this analysis, the data were frozen as of 31 December 2009.

In LSOCA, study visits were initially conducted every six months for individuals without an opportunistic ocular infection (OOI) and every three months for individuals with an OOI. As of 1 December 2008, all individuals, regardless of OOI status, were followed at six-month intervals. To eliminate the potential for bias due to unequal follow-up, only the six-month visits were included in this analysis. Individuals were considered to be lost to follow-up if three consecutive visits were missed, i.e. no visits occurred within the year and a half prior to the data freeze. The data collected included medical and ophthalmic history, Karnofsky score, and a complete ophthalmologic examination. Standardized descriptions of classical clinical features were used to diagnose CMV retinitis by LSOCA-certified ophthalmologists. ${ }^{16}$ Laboratory measurements included CD4+ T cell counts, CD8+ T cell counts, and plasma HIV load. In addition to being considered as a continuous measurement, CD4+ T cell counts were categorized as $\geq 100,50-99$, and $<50$ cells $/ \mu \mathrm{L}$. The threshold of $\geq 100$ cells/ $\mu \mathrm{L}$ was chosen since that is the level at which discontinuation of anti-CMV therapy is recommended. ${ }^{17-19}$ Previous studies in the pre-HAART era have indicated that additional risk is present for individuals with a CD4+ T cell count below 50 cells $/ \mu \mathrm{L}^{20}$ CMV load was available at each visit through 2003. The results presented here are based upon the 1,600 participants who were free from CMV retinitis at enrollment and who completed at least one follow-up visit.

The incidence rates for CMV retinitis are expressed as rates per 100 person years $(\mathrm{PY})^{21}$ and were calculated for the cohort and stratified by CD4+ T cell status at the visit prior to CMV retinitis evaluation ( $\geq 100,50-99$, or $<50$ cells $/ \mu L$ ). Staggered entry Kaplan-Meier curves ${ }^{22}$ were plotted to portray the cumulative probability of incident CMV retinitis over time and were anchored at the reported date of AIDS diagnosis. Univariate Cox proportional hazards models were used to compare the relative risks of acquiring CMV retinitis without adjusting for multiple comparisons. ${ }^{23}$ Risk factors with repeated measurements during the course of the study were analyzed as time-varying covariates. Of these, age at each visit, HAART, CD4+ T cell count, CD8+ T cell count, and HIV load were assessed at the visit prior to CMV retinitis evaluation (i.e., lagged by one visit). Analyses based upon the participants with complete data at baseline, missing values for time-varying covariates carried forward from the most recent clinic visit, and multiple imputation to account for missing data yielded similar results. Statistical analyses were performed with SAS (SAS/STAT User's Guide, Version 9.1, Cary, C: SAS Institute) and Stata (StataCorp, 2007, Stata Statistical Software: Release 10, College Station, TX: StatCorp LP) statistical packages.

\section{Results}

As of 31 December 2009, 2,271 participants with AIDS were enrolled in LSOCA, of whom 492 had CMV retinitis in at least one eye at enrollment. Of the remaining 1,779 individuals free of CMV retinitis at enrollment, 1,600 completed at least one follow-up visit. These individuals constitute the basis for our report. A total of 1,430 (89\%), 1,098 (69\%), 797 (50\%), and $80(5 \%)$ completed 1, 3, 5 and 10 years of follow-up, respectively, with a total of 8,134 person years of follow-up. The missed visit rate was 13\%, 337 individuals died, and an additional 329 were lost to follow-up (i.e. had not been seen for a minimum of 18 months). 


\section{Characteristics of the study population at enrollment and during follow-up}

The population characteristics at study entry and over the course of follow-up based upon the observed visits for individuals free from CMV retinitis at enrollment are reported in Table 1. The demographic characteristics observed in this cohort are comparable to those observed in other AIDS cohorts used to track CMV retinitis. ${ }^{1-2,6-11,13,18-20}$ In general, patients had long-standing disease with a median time from diagnosis of AIDS to enrollment of 4.4 years $\left(25^{\text {th }}-75^{\text {th }}\right.$ percentile: $\left.1.7-7.3\right)$. Most individuals were male $(80 \%)$, in particular males having sex with males (58\%), and the majority were non-Caucasian (54\%). The median CD8+ T cell count and nadir CD4+ T cell count as of enrollment were 776 cells $/ \mu \mathrm{L}\left(25^{\text {th }}-75^{\text {th }}\right.$ percentile: $\left.503-1,135\right)$ and 40 cells $/ \mu \mathrm{L}\left(25^{\text {th }}-75^{\text {th }}\right.$ percentile: $\left.12-104\right)$, respectively. The distributions of the time-varying CD8+ T cell counts and the time-updated nadir CD4+ T cell counts were similar to those observed at enrollment. Eighty-five percent of individuals were on HAART and $72 \%$ had a CD4+ T cell count of 100 cells $/ \mu \mathrm{L}$ or greater at enrollment with a higher fraction of each during the follow-up interval (93\% and $86 \%$, respectively). The median time since HAART initiation at enrollment was 2.9 years. However, the date of initiation is missing for $36 \%$ of the participants since this question was added during the course of the study. Despite widespread HAART usage, 34\% of participants had an HIV load greater than 10,000 copies/mL ( $>4$ on the $\log _{10}$ scale) at enrollment; however the percentage of the follow-up visits with HIV load greater than 10,000 copies $/ \mathrm{mL}$ was lower (19\%). CMV load was available for $67 \%$ of individuals at enrollment and $33 \%$ of the follow-up visits. The percentage with detectable samples ( $\geq 400$ copies $/ \mathrm{mL}$ ) was $2 \%$ and $1 \%$ for enrollment and follow-up visits, respectively.

\section{Epidemiologic risk of $\mathrm{CMV}$ retinitis}

During the 8,134 person-years of follow-up for individuals free from CMV retinitis at enrollment, 29 incident cases of CMV retinitis were observed, yielding a rate of 0.36 per $100 \mathrm{PY}$ with a cumulative incidence of $1.2 \%$ (95\% CI: $0.5 \%$ to $3.1 \%$ ) at 4 years and $4.2 \%$ (95\% CI: $2.7 \%$ to $6.3 \%$ ) at 10 years (Table 2). The rate was constant over time since AIDS diagnosis (Figure 1). The Kaplan-Meier estimates of cumulative incidence of CMV retinitis stratified by time-varying CD4+ T cell count are presented in Supplemental Figure 1. The incidence rate for those individuals with a CD4+ T cell count below 50 cells $/ \mu \mathrm{L}$ at the preceding visit was $3.89 / 100 \mathrm{PY}$, significantly higher than the overall rate $(\mathrm{p}<0.0001)$. Twenty-six (90\%) of the individuals who developed incident CMV retinitis had a CD4+ T cell count below 50 cells $/ \mu \mathrm{L}$ at the visit prior to detection as compared to $1(3 \%)$ with 50-99 cells $/ \mu \mathrm{L}$ and $2(7 \%)$ with $\geq 100$ cells $/ \mu \mathrm{L}$. For the three individuals who had CD4+ T cell counts 250 cells $/ \mu \mathrm{L}$ at the visit prior to the diagnosis of CMV retinitis, the onset of disease was well after the initial diagnosis with AIDS (4.6 and 4.9 years for the two individuals with CD4+ T cell counts $\geq 100$ cells $/ \mu \mathrm{L}$ and 12.9 years for the individual with CD4+ T cell count between 50-99 cells $/ \mu \mathrm{L}$ ). All 29 individuals who developed incident CMV retinitis had a CD4+ T cell count of less than 50 cells $/ \mu \mathrm{L}$ at some time prior to developing CMV retinitis. However, not all individuals who experienced that level of immunodeficiency went on to develop the disease. In fact, when restricting the analysis to all follow-up visits that occurred after a CD4+ T cell count less than 50 cells/ $\mu \mathrm{L}$ was observed, the incidence rate was $0.65 / 100 \mathrm{PY}$, slightly less than double the rate observed for population as a whole.

\section{Factors influencing risk of CMV retinitis}

The analysis of the risk factors associated with incident CMV retinitis is summarized in Table 3. In the univariate analysis, a Karnofsky score < 80 (HR: 2.2, 95\% CI: 1.01 to 4.6, p $=0.045$ ), the presence of HIV retinopathy (HR: 11.6, 95\% CI: 3.3 to 40.2, $\mathrm{p}=0.0001$ ), CD8+ T cell count $<400$ cells/ $\mu \mathrm{L}$ at the previous visit (HR 15.2, 95\% CI: 6.8 to 33.6, $\mathrm{p}<$ 0.0001 ), and HIV load $>10,000$ copies $/ \mathrm{mL}$ ( $>4$ on the $\log _{10}$ scale) at the previous visit (HR: 37, 95\% CI: 8 to $162, \mathrm{p}<0.0001$ ), CMV load at the previous visit (HR: 26, 95\% CI: 3 
to $186, \mathrm{p}=0.0014$ ) as well as $\mathrm{CD} 4+\mathrm{T}$ cell count less than 50 cells $/ \mu \mathrm{L}$ at the previous visit (HR: $136,95 \%$ CI: 30 to 605 , p < 0.0001) were associated with a significant increase in the risk of developing incident CMV retinitis. CD4+ T cell counts below 10 were not significantly associated with increased incidence when compared to counts of 10-49 (HR: $2.0,95 \%$ CI: 0.9 to $4.4, p=0.07)$. CD4+ T cell counts of $50-99$ cells $/ \mu \mathrm{L}$ at the previous visit were not significantly associated with an increase in incidence (HR: $6.4,95 \%$ CI: 0.5 to 73.2, $\mathrm{p}=0.14$ ), nor was treatment with HAART at the previous visit (HR: $0.6,95 \%$ CI: 0.1 to $1.6, \mathrm{p}=0.27$ ) or race (HR for non-Caucasian: $0.6,95 \%$ CI: 0.3 to $1.4, \mathrm{p}=0.22$ ). The HIV exposure men having sex with men was associated with an increased risk that was of borderline statistical significance (HR: 2.2, 95\% CI: 0.9 to $5.2, \mathrm{p}=0.064$ ). Older age was associated with a significant decrease in risk (HR per 10 years: $0.6,95 \%$ CI: 0.4 to $0.8, \mathrm{p}<$ 0.0001). Large multivariate models were not considered appropriate for analysis due to the potential for multiple risk profiles with zero events based upon the small number of events and the co-linearity of the risk factors. Pairwise models, including CD4+ T cell counts plus one other variable, were fit for each of the significant risk factors. CD4+ T cell counts remained significant but the magnitude of the risk for the other variables was attenuated and became non-significant for all other variables (results not shown). Analyses restricting the risk set to those who had a nadir CD4+ T-cell count below 50 cells $/ \mu \mathrm{L}$ produced similar findings (results not shown).

\section{Discussion}

CMV retinitis remains a risk factor for mortality and vision loss in the HAART era. ${ }^{10-12}$ Previous studies have focused upon the incidence rates in the pre-HAART $\mathrm{era}^{2}$ or computed estimates based upon the prevalence in the HAART era. ${ }^{13}$ This analysis provides a prospective examination of the incidence rate of and the corresponding risk factors for developing CMV retinitis among individuals with AIDS in the HAART era.

These data quantify the substantial decrease in the incidence of CMV retinitis when compared to the incidence observed in the pre-HAART era. In the pre-HAART era, Hoover et $\mathrm{al}^{2}$ investigated the cumulative incidence of CMV retinitis for individuals following a diagnosis of immune suppression, defined as having a CD4+ T cell count below 100 cells/ $\mu \mathrm{L}$. The 4-year cumulative incidence was $25 \%$ as compared to $7 \%$ for LSOCA, a $72 \%$ reduction. In fact, only $12 \%$ of individuals in LSOCA who had severe immunodeficiency (i.e., a CD4+ T cell count below 50 cells $/ \mu \mathrm{L}$ ) developed $\mathrm{CMV}$ retinitis during the first 4 years of following the diagnosis of AIDS, a 52\% reduction (Table 2).

In a cross-sectional analysis of the LSOCA data at enrollment, the CMV retinitis incident rate was estimated to be 5.6/100 PY (95\% CI: 5.0-6.2). ${ }^{13}$ The observed incidence rate during follow-up in LSOCA was $0.4 / 100 \mathrm{PY}$, a $93 \%$ reduction. The increase in the estimate of the incidence rate in the cross-sectional analysis may be due in part to referral bias. Patients were recruited from ophthalmology clinics specializing in infectious disease or retinal clinics, thereby enriching the population of individuals with opportunistic ocular infections including CMV retinitis. Although we would not expect to observe as large an influence on the incident as compared to prevalence, the estimates of incident infection may also be inflated relative to the general population of patients with AIDS for the same reason.

The greatest identified risk factor for incident CMV retinitis was having a CD4+ T cell count below 50 cells $/ \mu \mathrm{L}$ at the prior visit (HR: $136,95 \%$ CI: 30 to $605, \mathrm{p}<0.0001$ ), although the estimate lacks precision due to the small number of observed incident cases. Pertel et al also observed an increased risk for patients with a CD4+ T cell count below 50 cells $/ \mu \mathrm{L}$ in the pre-HAART era, although not of the same magnitude (OR: 4.62) ${ }^{20}$ Prior to the development of HAART therapy, a decline in CD4+ T cell count to below 50 cells $/ \mu \mathrm{L}$ 
would be expected over the course of the disease. In general, HAART therapy raises CD4+ $\mathrm{T}$ cell counts causing a reduction in the proportion of the population with CD4+ T cell counts below 50 cells $/ \mu \mathrm{L}$ and therefore a decline in the incident rate of CMV retinitis. Given the widespread usage of HAART in our cohort, it seems likely that individuals with extremely low CD4+ T cell counts are either non-adherent or HAART resistant, perhaps indicative of more severe disease. Therefore, it is likely that individuals in our population with CD4+ T cell counts below 50 represent a higher risk cohort than that examined by Pertel et al, which would account for the difference in the observed risks. Low CD4+ T cell counts are also associated with increased risk of death, retinitis progression, retinal detachment, and decline in visual acuity. ${ }^{11}$

The effects of HAART in patients with CMV retinitis have been attributed largely to the induction of a $\mathrm{CD} 4+\mathrm{T}$ cell response, although a return to $\mathrm{CD} 4+\mathrm{T}$ cell levels above the threshold associated with treatment ( 2100 cells $/ \mu \mathrm{L}$ ) may not be essential. Previous studies have demonstrated that HAART is associated with improved survival, ${ }^{3,24}$ decreased rates of visual acuity loss, ${ }^{10,12}$ decreased risk of retinal detachment, ${ }^{25}$ and decreased rates of retinitis progression ${ }^{18}$ in patients with $\mathrm{CMV}$, independent of achieving this threshold. Our findings are consistent with these results since a significant increase in risk was not observed until the CD4+ T cell count fell below 50 cells/ $\mu \mathrm{L}$, which is below the cut-off associated with treatment $(100$ cells $/ \mu \mathrm{L})$. In general, those individuals who developed CMV retinitis had CD4+ T cell counts below 50 cells/ $\mu \mathrm{L}$ at the prior visit $(26 / 29,90 \%)$. Such individuals typically also had elevated HIV load and low CD8+ T cell counts. Nevertheless, $85 \%$ (22/26) were listed as being on HAART at the visit prior to CMV retinitis detection, indicating HAART failure or lack of adherence. This result supports the findings of prior research (based upon case studies, cross-sectional and retrospective cohorts, or the second eye for individuals with unilateral CMV retinitis) which noted that patients were at risk for developing CMV retinitis either because of delayed diagnosis of HIV infection or because they were noncompliant, intolerant of, or unresponsive to HAART. ${ }^{6-9}$

Many of the previously identified factors associated with CMV retinitis disease and progression were associated with disease incidence. Tay-Kearney et $\mathrm{al}^{26}$ reported that individuals with CMV retinitis had lower CD8+ T cell counts as compared to with those without CMV retinitis among HIV positive individuals with CD4+ T cell counts less than 50 cells $/ \mu \mathrm{L}$. The hazard ratio associated with a CD8+ T cell count below 400 cells $/ \mu \mathrm{L}$ among individuals with CD4+ T cell counts below 50 cells $/ \mu \mathrm{L}$ was 11 (95\% CI: 5 to $253, \mathrm{p}<$ 0.0001 ), which is similar to the overall effect (Table 3). HIV load might be expected to be associated with increased risk due to transactivation of the respective viruses. In our cohort, an HIV load greater than 10,000 copies $/ \mathrm{mL}$ ( 4 on the $\log 10$ scale) was associated with a significant increase in the risk of incident CMV retinitis (HR: 37, p < 0.0001). HIV retinopathy has been observed to be associated with CMV retinitis and was a risk factor associated with incident disease. ${ }^{1}$

Incident CMV retinitis did not occur in the prospective cohort until an individual had recorded a nadir CD4+ T cell count less than 50 cells/ $\mu \mathrm{L}(0 / 29,0 \%, 95 \% \mathrm{CI}: 0-12 \%)$. The upper bound of the $95 \%$ confidence interval, although low, is consistent with the fraction of individuals diagnosed with CMV retinitis with a nadir CD4+ T cell count at or above 50 cells $/ \mu \mathrm{L}$ observed by Hoover et al ${ }^{2}(19 \%)$ and LSOCA at enrollment ${ }^{11}(14 \%$ for newly diagnosed and $16 \%$ for long-standing CMV retinitis). Therefore, although we cannot conclude that a nadir CD4+ T cell count below 50 cells/ $\mu \mathrm{L}$ is a necessary condition for developing incident CMV retinitis, diagnoses of CMV retinitis in the presence of nadir CD4+ T cell counts $\geq 50$ cells $/ \mu \mathrm{L}$ are uncommon in populations treated with HAART. 
Anti-CMV antibody status was not evaluated during the course of the study. However, previous studies in AIDS $^{27}$ and homosexual ${ }^{28}$ men have reported high rates of anti-CMV antibodies (90\% and 94\%, respectively). ${ }^{28} \mathrm{CMV}$ viral load was only collected through 2003. Although detectable CMV load was associated with an increased risk of incident CMV retinitis, the clinical utility may be limited due to the poor sensitivity of the test. Of the 20 cases evaluable for CMV load within a year of diagnosis, $12(60 \%)$ had undetectable CMV loads at all visits including those at and following diagnosis.

The LSOCA cohort provides a unique opportunity to observe incident CMV retinitis among AIDS patients in the HAART era with a total of 1,600 patients who enrolled without CMV retinitis and completed at least one follow-up visit. However, due to the small number of observed incident cases, the estimates may lack precision, especially 10 or more years beyond the reported date of AIDS diagnosis, during which period only 5 incident cases were observed (Table 3, Figure 1). As noted above, the small number of incident cases also limits the ability to evaluate multiple risk factors simultaneously.

In conclusion, although greatly reduced, CMV retinitis continues to be observed in patients with AIDS in the HAART era, particularly among those with severely compromised immune systems. In fact, the cumulative 10- and 15-year rates remain substantial for those with CD4+ T cell counts below 50 cells/ $\mu \mathrm{L}$ at the prior visit (34\% and 44\%, respectively). Therefore, the screening recommendations ${ }^{29}$ for patients with AIDS and low CD4+ T cell counts should not be changed even in the current HAART era.

\section{Supplementary Material}

Refer to Web version on PubMed Central for supplementary material.

\section{Acknowledgments}

Funding: Supported by cooperative agreements from the National Eye Institute, the National Institutes of Health, Bethesda, MD, to the Johns Hopkins University Bloomberg School of Public Health, Baltimore, MD (U10 EY08057); to the Mount Sinai School of Medicine, New York, NY (U10 EY08052); and the University of Wisconsin, Madison, Madison, WI (U10 EY08067). Dr. Thorne is the recipient of a Research to Prevent Blindness (RPB) Sybil B. Harrington Special Scholars Award.

Other Acknowledgments: None.

\section{References}

1. Jabs DA. Ocular manifestations of HIV infection. Trans Am Ophthalmol Soc. 1995; 93:623-683. [PubMed: 8719695]

2. Hoover DR, Peng Y, Saah A, et al. Occurrence of cytomegalovirus retinitis after human immunodeficiency virus immunosuppression. Arch Ophthalmol. 1996; 114(7):821-827. [PubMed: 8660165]

3. Deayton JR, Wilson P, Sabin CA, et al. Changes in the natural history of cytomegalovirus retinitis following the introduction of highly active antiretroviral therapy. AIDS. 2000; 14(9):1163-1170. [PubMed: 10894280]

4. Jacobson MA, Stanley H, Holtzer C, et al. Natural history and outcome of new AIDS-related cytomegalovirus retinitis diagnosed in the era of highly active antiretroviral therapy. Clin Infect Dis. 2000; 30(1):231-233. [PubMed: 10619774]

5. Holtzer CD, Jacobson MA, Hadley WK, et al. Decline in the rate of specific opportunistic infections at San Francisco General Hospital, 1994-1997. AIDS. 1998; 12(14):1931-1933. [PubMed: 9792398] 
6. Jabs DA, Van Natta ML, Kempen JH, et al. Characteristics of patients with cytomegalovirus retinitis in the era of highly active antiretroviral therapy. Am J Ophthalmol. 2002; 133(1):48-61. [PubMed: 11755839]

7. Kempen JH, Jabs DA, Wilson LA, et al. Incidence of cytomegalovirus (CMV) retinitis in second eyes of patients with the acquired immune deficiency syndrome and unilateral CMV retinitis. Am J Ophthalmol. 2005; 139(6):1028-1034. [PubMed: 15953432]

8. Holland GN, Vaudaux JD, Shiramizu KM, et al. Characteristics of untreated AIDS-related cytomegalovirus retinitis. II. Findings in the era of highly active antiretroviral therapy (1997 to 2000). Am J Ophthalmol. 2008; 145(1):12-22. [PubMed: 18154751]

9. Komanduri KV, Feinberg J, Hutchins RK, et al. Loss of cytomegalovirus-specific CD4+ T cell responses in human immunodeficiency virus type 1-infected patients with high CD4+ T cell counts and recurrent retinitis. J Infect Dis. 2001; 183(8):1285-1289. [PubMed: 11262214]

10. Thorne JE, Jabs DA, Kempen JH, et al. Incidence of and risk factors for visual acuity loss among patients with AIDS and cytomegalovirus retinitis in the era of highly active antiretroviral therapy. Ophthalmology. 2006; 113(8):1432-1440. [PubMed: 16766032]

11. Jabs DA, Ahuja A, Van Natta M, et al. Course of cytomegalovirus retinitis in the era of highly active antiretroviral therapy: five-year outcomes. Ophthalmology. 2010; 117(11):2152-2161. [PubMed: 20673591]

12. Kempen JH, Jabs DA, Wilson LA, et al. Risk of vision loss in patients with cytomegalovirus retinitis and the acquired immunodeficiency syndrome. Arch Ophthalmol. 2003; 121(4):466-476. [PubMed: 12695243]

13. Jabs DA, Van Natta ML, Holbrook JT, et al. Longitudinal study of the ocular complications of AIDS: 1. Ocular diagnoses at enrollment. Ophthalmology. 2007; 114(4):780-786. [PubMed: 17258320]

14. Jabs DA, Van Natta ML, Holbrook JT, et al. Studies of the Ocular Complications of AIDS Research Group. Longitudinal Study of the Ocular Complications of AIDS: 2. Ocular examination results at enrollment. Ophthalmology. 2007; 114(4):787-793. [PubMed: 17210182]

15. Castro KG, Ward JW, Slutsker L, et al. 1993 revised classification system for HIV infection and expanded surveillance case definition for AIDS among adolescents and adults. MMWR Recomm Rep. 1992; 41(RR-17):1-19.

16. AIDS Clinical Trials Group (ACTG). Studies of ocular complications of AIDS FoscarnetGanciclovir Cytomegalovirus Retinitis Trial: 1. Rationale, design, and methods. Control Clin Trials. 1992; 13(1):22-39. [PubMed: 1315661]

17. Centers for Disease Control and Prevention. Group Guidelines for Prevention and Treatment of Opportunistic Infections in HIV-infected Adults and Adolescents. Morbid Mortal Weekly Rep. 2009; 58(3):55-60.

18. Jabs DA, Van Natta ML, Thorne JE, et al. Course of cytomegalovirus retinitis in the era of highly active antiretroviral therapy: 1. Retinitis progression. Ophthalmology. 2004; 111(12):2224-2231. [PubMed: 15582078]

19. Kempen JH, Min Y-I, Freeman WR, et al. Risk of immune recovery uveitis in patients with AIDS and CMV retinitis. Ophthalmology. 2006; 113(4):684-694. [PubMed: 16581429]

20. Pertel P, Hirschtick R, Phair J, et al. Risk of developing cytomegalovirus retinitis in persons infected with the human immunodeficiency virus. JAIDS. 1992; 5(11):1069-1074.

21. Altman, DG. Practical Statistics for Medical Research. London: Chapman and Hall; 1991. p. 213-5.p. 241-256.

22. Kaplan EL, Meier P. Non-parametric estimation from incomplete observations. J Am Stat Assoc. 1958; 53(282):457-481.

23. Cox, DR.; Oakes, D. Analysis of Survival Data. London: Chapman and Hall; 1984. p. 248-275.

24. Kempen JH, Jabs DA, Wilson LA, et al. Mortality risk for patients with cytomegalovirus retinitis and acquired immune deficiency syndrome. Clin Infect Dis. 2003; 37(10):1365-1373. [PubMed: $14583871]$

25. Kempen JH, Jabs DA, Dunn JP, et al. Retinal detachment risk in cytomegalovirus retinitis related to the aquired immunodeficiency syndrome. Arch Ophthalmol. 2001; 119(1):33-40. [PubMed: 11146724] 
26. Tay-Kearney M-L, Enger C, Semba RD, et al. T cell subsets and cytomegalovirus retinitis in human immunodeficiency virus-infected patients. J Infect Diseases. 1997; 176(3):790-794. [PubMed: 9291335]

27. Mhalu F, Haukenes. Prevalence of cytomegalovirus antibody in pregnant women, AIDS patients, and STD patients in Dar es Salaam. AIDS. 1990; 4(12):1294-1295. [PubMed: 1965127]

28. Drew WL, Mintz L, Miner RC, et al. Prevalence of cytomegalovirus infection in homosexual men. J Infect Dis. 1981; 143(2):188-192. [PubMed: 6260871]

29. Whitley RJ, Jacobson MA, Friedberg DN, et al. Guidelines for the treatment of cytomegalovirus diseases in patients with AIDS in the era of potent antiretroviral therapy: recommendations of an international panel. Arch Intern Med. 1998; 158(9):957-969. [PubMed: 9588429]

\section{Biographies}

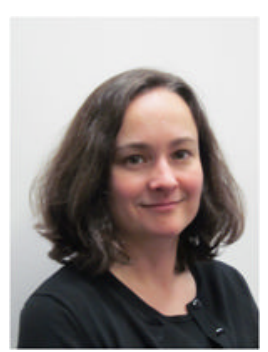

Elizabeth A Sugar, PhD, is an Assistant Scientist in the Departments of Epidemiology and Biostatistics at the Bloomberg School of Public Health at Johns Hopkins University. She is the Chair of the Statistical Committee for the Multicenter Uveitis Steroid Treatment Trial and is involved in The Studies of the Ocular Complications of AIDS. Her interests include the design, analysis and interpretation of clinical trials and epidemiologic studies in ophthalmology, asthma, oncology, and AIDS.

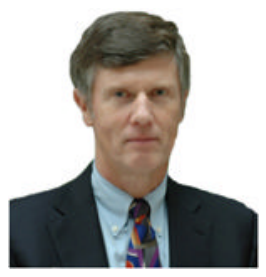

Douglas A. Jabs, MD, MBA, is the Chief Executive Office of the Mount Sinai Faculty Practice Associates, Dean for Clinical Affairs, and Professor and Chairman of the Department of Ophthalmology at Mount Sinai School of Medicine, New York, New York. He is the study chair of The Studies of the Ocular Complications of AIDS, the Multicenter Uveitis Steroid Treatment Trial, and the Standardization of Uveitis Nomenclature project. His interests include uveitis, epidemiology, and clinical trials. 


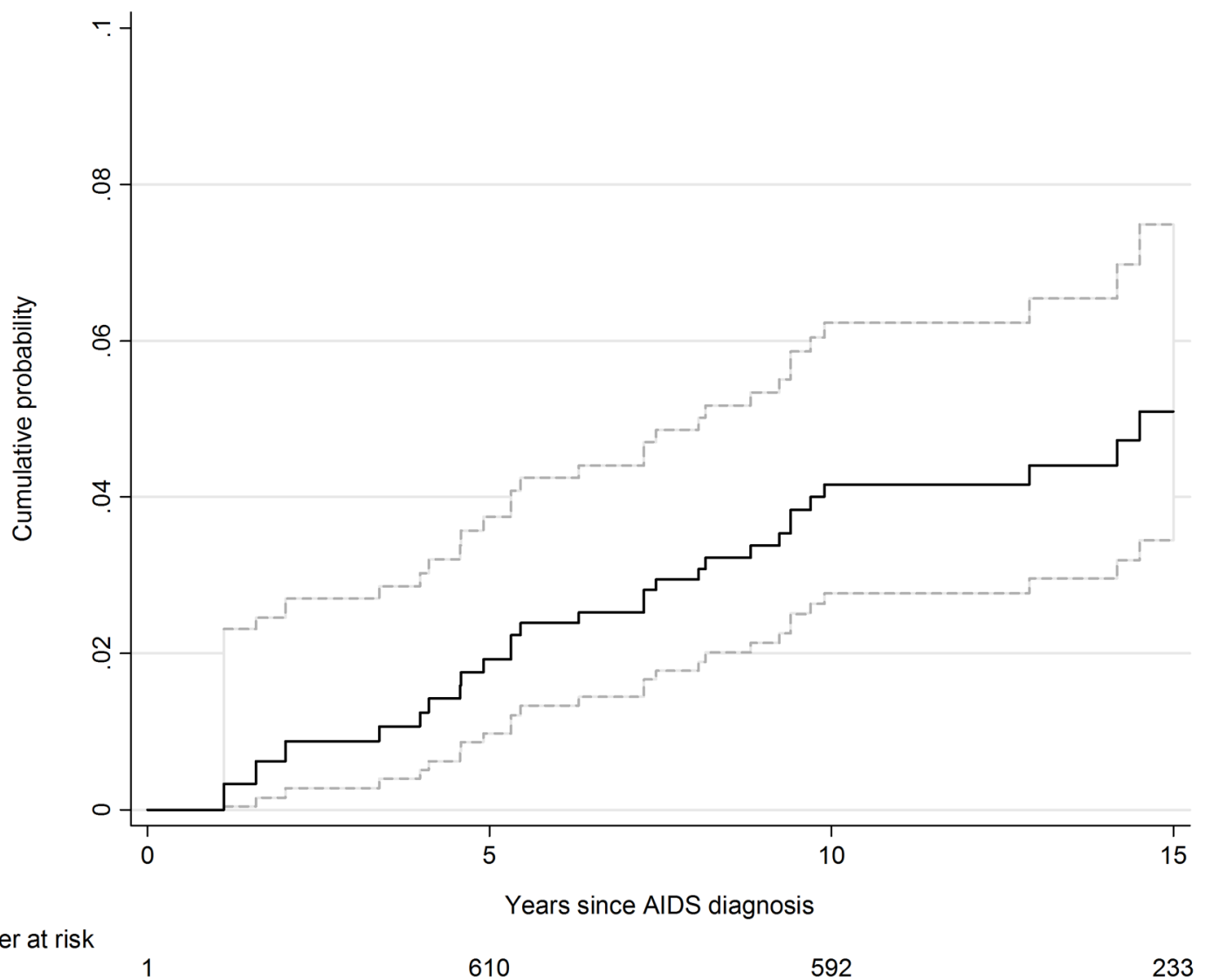

Figure 1.

Incident cytomegalovirus (CMV) retinitis among eyes free from CMV retinitis at enrollment. Follow-up is measured from the reported date of AIDS diagnosis. The dotted lines represent the upper and lower bounds of the $95 \%$ confidence interval. 
Table 1

Enrollment and follow-up characteristics of participants with AIDS enrolled in the Longitudinal Studies of Ocular Complications of AIDS without cytomegalovirus retinitis

\begin{tabular}{|c|c|c|}
\hline Characteristic & Participants $(\mathrm{N}=1,600)$ & Person-visits $(N=14,311)$ \\
\hline Median age, years ${ }^{a}$ & $43(38$ to 49$)$ & \\
\hline Median years since AIDS diagnosis ${ }^{a}$ & $4.4(1.7$ to 7.3$)$ & \\
\hline Missing, $\mathrm{n}(\%)^{b}$ & $17(1 \%)$ & \\
\hline Median years since HAART initiation at enrollment ${ }^{a}$ & $2.9(1.0$ to 5.1$)$ & \\
\hline Missing, $\mathrm{n}(\%)^{b}$ & $570(36 \%)$ & \\
\hline \multicolumn{3}{|l|}{ Gender, $\mathrm{n}(\%)^{b}$} \\
\hline Female & $312(20 \%)$ & \\
\hline Male & $1,288(80 \%)$ & \\
\hline \multicolumn{3}{|l|}{ Race, $\mathrm{n}(\%)^{b}$} \\
\hline Caucasian, non-Hispanic & $734(46 \%)$ & \\
\hline Non-caucasian & $866(54 \%)$ & \\
\hline \multicolumn{3}{|l|}{ HIV exposure category, $\mathrm{n}(\%)^{b}$} \\
\hline Other & $667(42 \%)$ & \\
\hline Men having sex with men & $933(58 \%)$ & \\
\hline \multicolumn{3}{|l|}{ AIDS defining illness, $\mathrm{n}(\%)^{b}$} \\
\hline $\mathrm{T}$ cell lymphopenia & $1,030(65 \%)$ & \\
\hline Opportunistic infection/neoplasm & $558(35 \%)$ & \\
\hline Missing & $12(1 \%)$ & \\
\hline \multicolumn{3}{|l|}{ Karnofsky score, $\mathrm{n}(\%)^{b}$} \\
\hline $90-100$ & $819(51 \%)$ & \\
\hline$\leq 80$ & $781(49 \%)$ & \\
\hline HIV retinopathy, $\mathrm{n}(\% \text { yes })^{b}$ & $46(3 \%)$ & $131(1 \%)$ \\
\hline Missing & $0(0 \%)$ & $248(2 \%)$ \\
\hline HAART, n (\% yes) $b$ & $1,356(85 \%)$ & $13,106(93 \%)$ \\
\hline Missing & $1(0 \%)$ & $235(2 \%)$ \\
\hline \multicolumn{3}{|l|}{ Nadir CD4+ T cell count } \\
\hline Median $(\text { cells } / \mu \mathrm{L})^{a}$ & 40 (12 to 104$)$ & $37(11$ to 97$)$ \\
\hline \multicolumn{3}{|l|}{ Cells/ $\mu L, n(\%)^{b}$} \\
\hline$\geq 100$ cells $/ \mu \mathrm{L}$ & $411(26 \%)$ & $3,406(24 \%)$ \\
\hline $50-100$ cells $/ \mu \mathrm{L}$ & $292(19 \%)$ & $2,629(19 \%)$ \\
\hline$<50$ cells $/ \mu \mathrm{L}$ & $875(55 \%)$ & $8,007(57 \%)$ \\
\hline Missing & $22(1 \%)$ & $270(2 \%)$ \\
\hline \multicolumn{3}{|l|}{ CD4+ T cell count } \\
\hline Median $(\operatorname{cells} / \mu \mathrm{L})^{a}$ & 197 (81 to 360$)$ & 324 (172 to 491$)$ \\
\hline \multicolumn{3}{|l|}{ Cells/ $\mu L, n(\%)^{b}$} \\
\hline$\geq 100$ cells $/ \mu \mathrm{L}$ & $1,142(72 \%)$ & $12,066(86 \%)$ \\
\hline
\end{tabular}




\begin{tabular}{|c|c|c|}
\hline Characteristic & Participants $(N=1,600)$ & Person-visits $(N=14,311)$ \\
\hline $50-100$ cells $/ \mu \mathrm{L}$ & $178(11 \%)$ & $824(6 \%)$ \\
\hline$<50$ cells $/ \mu \mathrm{L}$ & $268(17 \%)$ & $1,093(8 \%)$ \\
\hline Missing & $12(1 \%)$ & $329(2 \%)$ \\
\hline \multicolumn{3}{|l|}{$\mathrm{CD} 8+\mathrm{T}$ cell count } \\
\hline Median $(\text { cells } / \mu \mathrm{L})^{a}$ & $776(503$ to 1,135$)$ & 827 (568 to 1,152$)$ \\
\hline \multicolumn{3}{|l|}{ Cells $/ \mu L, n(\%)^{b}$} \\
\hline$\geq 400$ cells $/ \mu \mathrm{L}$ & $1,327(84 \%)$ & $12,045(88 \%)$ \\
\hline$<400$ cells $/ \mu \mathrm{L}$ & $253(16 \%)$ & $1637(12 \%)$ \\
\hline Missing & $20(1 \%)$ & $630(4 \%)$ \\
\hline \multicolumn{3}{|l|}{ HIV load } \\
\hline Median $\left(\log _{10}[\text { copies } / \mathrm{mL}]\right)^{a}$ & 2.7 (1.9 to 4.6$)$ & $2.3(1.7$ to 3.3$)$ \\
\hline \multicolumn{3}{|l|}{$\log _{10}[$ copies $/ \mathrm{mL}], n(\%)^{b}$} \\
\hline$<2.6$ (undetectable) & $716(47 \%)$ & $8,922(67 \%)$ \\
\hline $2.6-4.0$ & $298(19 \%)$ & $1,847(14 \%)$ \\
\hline 4.0 & $519(34 \%)$ & $2,517(19 \%)$ \\
\hline Missing & $67(4 \%)$ & $1,026(7 \%)$ \\
\hline \multicolumn{3}{|l|}{ CMV load, $\mathrm{n}(\%)^{b}$} \\
\hline Undetectable $(<400$ copies $/ \mathrm{mL})$ & $1081(98 \%)$ & $3320(99 \%)$ \\
\hline Detectable ( $\geq 400$ copies $/ \mathrm{mL}$ ) & $20(2 \%)$ & $31(1 \%)$ \\
\hline Missing & $500(33 \%)$ & $10962(77 \%)$ \\
\hline
\end{tabular}

$a_{\text {The }} 25^{\text {th }}-75^{\text {th }}$ percentiles are included in parentheses with the median.

$b$ Percentages of missing values are calculated out of the total sample size. Percentages for categories are calculated out of the total sample of nonmissing values.

AIDS = acquired immune deficiency syndrome; HIV = human immunodeficiency syndrome; HAART = highly active antiretroviral therapy; CMV $=$ cytomegalovirus. 
Table 2

Cumulative incidence of cytomegalovirus (CMV) retinitis in the Longitudinal Studies of the Ocular Complications of AIDS cohort

\begin{tabular}{|c|c|c|c|}
\hline & $\begin{array}{c}\text { Number of CMV Retinitis } \\
\text { Incidence Cases }\end{array}$ & 4-year Cumulative Incidence ${ }^{d}(95 \%$ CI $)$ & 10-year Cumulative Incidence ${ }^{d}(95 \%$ CI $)$ \\
\hline Overall & 29 & $1.2 \%(0.5 \%$ to $3.1 \%)$ & $4.2 \%(2.7 \%$ to $6.3 \%)$ \\
\hline \multicolumn{4}{|c|}{ CD4+ T cell count ${ }^{a}$} \\
\hline$\geq 100$ cells $/ \mu \mathrm{L}^{b}$ & 2 & 0 & $0.3 \%(0.1 \%$ to $1.7 \%)$ \\
\hline $50-99$ cells $/ \mu L^{c}$ & 1 & 0 & 0 \\
\hline$<50$ cells $/ \mu \mathrm{L}$ & 26 & $12.3 \%(5.1 \%$ to $27.9 \%)$ & $33.6 \%(23.2 \%$ to $47.0 \%)$ \\
\hline
\end{tabular}

${ }^{a} \mathrm{CD} 4+\mathrm{T}$ cell count is evaluated at the visit prior to CMV retinitis evaluation (i.e. lagged by one visit).

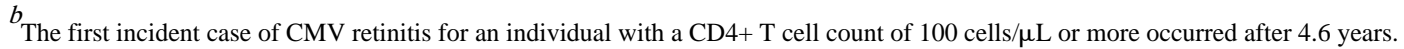

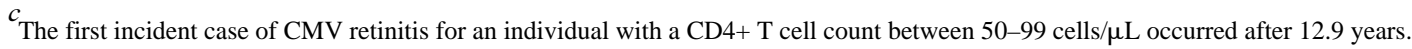

${ }^{d}$ Cumulative incidence with $95 \%$ confidence intervals are calculated using staggered entry Kaplan-Meier estimates anchored at the reported date of AIDS diagnosis.

$\mathrm{CMV}=$ cytomegalovirus; AIDS = acquired immune deficiency syndrome; $\mathrm{CI}=$ confidence interval. 
Table 3

Rates and crude hazard ratios for incident cytomegalovirus retinitis for select risk factors

\begin{tabular}{|c|c|c|c|c|}
\hline \multirow{2}{*}{$\begin{array}{l}\text { Risk factor } \\
\text { Age (per } 10 \text { years) })^{a, b}\end{array}$} & \multicolumn{2}{|c|}{ Events per 100 PY (\# Events/PY) } & \multirow{2}{*}{ 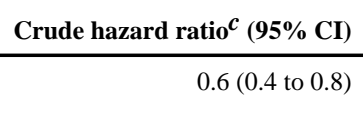 } & \multirow{2}{*}{$\frac{\text { P-value }}{<0.0001}$} \\
\hline & $\mathrm{n} / \mathrm{a}$ & $\mathrm{n} / \mathrm{a}$ & & \\
\hline \multicolumn{5}{|l|}{ Race } \\
\hline Caucasian, non-Hispanic & 0.44 & $(17 / 3908)$ & 1.0 & \\
\hline Non-Caucasian & 0.29 & $(12 / 4145)$ & $0.6(0.3$ to 1.4$)$ & 0.22 \\
\hline \multicolumn{5}{|l|}{ HIV exposure category } \\
\hline Other & 0.22 & $(7 / 3167)$ & 1.0 & 0.064 \\
\hline Men having sex with men & 0.45 & $(22 / 4885)$ & $2.2(0.9$ to 5.2$)$ & \\
\hline \multicolumn{5}{|l|}{ Karnofsky score } \\
\hline $90-100$ & 0.24 & $(11 / 4607)$ & 1.0 & 0.045 \\
\hline$\leq 80$ & 0.52 & $(18 / 3445)$ & $2.2(1.01$ to 4.6$)$ & \\
\hline \multicolumn{5}{|l|}{ HIV retinopathy ${ }^{a}$} \\
\hline No & 0.33 & $(26 / 7973)$ & 1.0 & \\
\hline Yes & 3.80 & $(3 / 79)$ & $11.6(3.3$ to 40.2$)$ & 0.0001 \\
\hline \multicolumn{5}{|l|}{ HAART $^{a}$} \\
\hline No & 0.61 & $(4 / 654)$ & 1.0 & \\
\hline Yes & 0.31 & $(25 / 7398)$ & $0.6(0.1$ to 1.6$)$ & 0.27 \\
\hline \multicolumn{5}{|l|}{ CD4+ $T$ cell count ${ }^{a}$} \\
\hline$\geq 100$ cells $/ \mu \mathrm{L}$ & 0.03 & $(2 / 6826)$ & 1.0 & \\
\hline $50-99$ cells $/ \mu \mathrm{L}$ & 0.18 & $(1 / 551)$ & $6.4(0.5$ to 73.2$)$ & 0.14 \\
\hline$<50$ cells $/ \mu \mathrm{L}$ & 3.89 & $(26 / 669)$ & $136(30$ to 605$)$ & $<0.0001$ \\
\hline \multicolumn{5}{|l|}{ CD8 $+T$ cell count ${ }^{a}$} \\
\hline$\geq 400$ cells $/ \mu \mathrm{L}$ & 0.13 & $(9 / 7076)$ & 1.0 & \\
\hline$<400$ cells $/ \mu \mathrm{L}$ & 1.99 & $(19 / 955)$ & $15.2(6.8$ to 33.6$)$ & $<0.0001$ \\
\hline \multicolumn{5}{|l|}{ HIV load $\left[\log _{10}(\operatorname{copies} / \mathrm{mL})\right]^{a}$} \\
\hline$<2.6$ copies $/ \mathrm{mL}$ & 0.04 & $(2 / 5017)$ & 1.0 & \\
\hline $2.6-4.0$ copies $/ \mathrm{mL}$ & 0.08 & $(1 / 1250)$ & $2.1(0.1$ to 22.8$)$ & 0.55 \\
\hline$>4.0$ copies $/ \mathrm{mL}$ & 1.47 & $(25 / 1696)$ & 37 (8 to 162$)$ & $<0.0001$ \\
\hline \multicolumn{5}{|l|}{ CMV load, n $(\%)^{a}$} \\
\hline Undetectable $(<400$ copies $/ \mathrm{mL})$ & 0.52 & $(9 / 1659)$ & 1.0 & \\
\hline Detectable ( 2400 copies $/ \mathrm{mL}$ ) & 6.67 & $(1 / 15)$ & 26 (3 to 186$)$ & 0.0014 \\
\hline
\end{tabular}

${ }^{a}$ Age, HIV retinopathy, HAART, CD4+ T cell count, CD8+ T cell count, HIV load and CMV load are time-varying covariates. All time-varying covariates except HIV retinopathy were lagged by one visit.

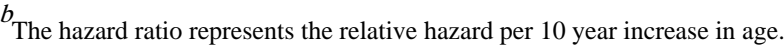

$\mathcal{c}$ The crude hazard ratios were computed using univariate Cox proportional hazards models without adjusting for multiple comparisons.

$\mathrm{HIV}=$ human immunodeficiency syndrome; HAART = highly active antiretroviral therapy; $\mathrm{PY}=$ person year; $\mathrm{CI}=$ confidence interval; $\mathrm{CMV}=$ cytomegalovirus. 